\title{
Research on the Flow Field and Structure Optimization in Cyclone Separator with Downward Exhaust Gas
}

\author{
Weiwei Wang ${ }^{1}$, Linjiang Zou ${ }^{1 *}$, Jun $\mathrm{Li}^{1}$ and Zhiming Zhao ${ }^{1}$ \\ ${ }^{1}$ School of Energy and Environment, Anhui University of Technology, Ma'an shan, 243002, China
}

\begin{abstract}
A numerical software analysis of the turbulent and strongly swirling flow field of a cyclone separator with downward exhaust gas and its performances is described. The ANSYS 14.0 simulations based on DPM model are also used in the investigation. A new set of geometrical design has been optimized to achieve minimum pressure drop and maximum separation efficiency. A comparison of numerical simulation of the new design confirm the superior performance of the new design compared to the conventional design. The influence of the structure parameters such as the length of the guide pipe, the shape of the guide, the inlet shape on the separation performance was analyzed in this research. This research result has certain reference value for cyclone separator design and performance optimization.
\end{abstract}

\section{Introduction}

Gas cyclone separators are widely used in industries to separate dust from gas due to their geometrical simplicity and relative economy in power consumption[1]. Currently, with the speeding up of the exhaustion of global energy resources, environmental pollution has become the focus of world[2]. Cyclone separator with downward exhaust gas has some advantages such as small flow resistance, low pressure loss and relatively low cost; And it is able to meet the requirements of $\prod$ type in the circulating fluidized bed boiler; while separation efficiency and ensure lower pressure loss at the same time, further study of the fine particles separation mechanism with the separator and the structure optimization design are needed[3].

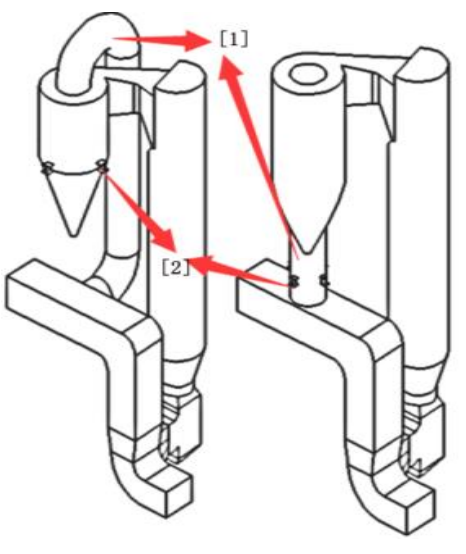

[1] Exhaust pipe [2] Supporting position

Figure 1. Comparison of cyclone separator with the downward and upward exhaust gas

As we can see from Fig.1, It is the arrangement of the circulating fluidized bed (CFB) boiler on flue gas dust removal device with semi dry desulfurization. It is shown that three elbows are less than the upward exhaust pipe of cyclone separator, and the length of the exhaust pipe is

\footnotetext{
${ }^{*}$ Conrresponding author: wahut@sina.com
} 
much longer than that of the downward exhaust pipe. Therefore, the overall resistance losses will be much greater than the downward exhaust pipe, and based on the structure features of the exhaust separator, it's the overall layout also more flexible[4]. However, due to the vortex change of the flow field, particle entrainment phenomenon is relatively serious in the downward exhaust gas, and the separation efficiency is smaller than that of the upward exhaust gas[5]. Thus to obtain the best separation performance, and meet the needs of the actual operation, it is necessary to optimize the design of the structure in this paper.

\section{Numerical models and boundary conditions}

\subsection{Physical model}

The Fig. 2 shows the schematic of the reference cyclone separator which is applied to some $400 t / h$ CFB boiler. The power plant uses coal gangue as fuel, and CFB boiler adopting the cyclone separator with downward exhaust gas.
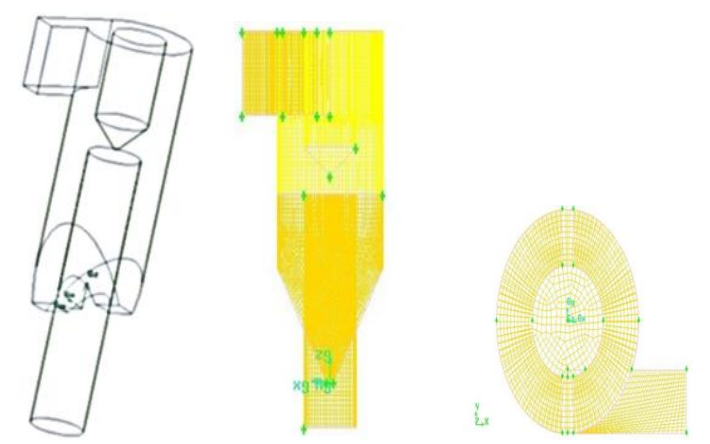

Figure 2. Schematic diagram of reference cyclone structure and grids of filter vessel.

\subsection{Simulation condition}

Due to the gas flow of the cyclone separator is a three dimensional turbulent flow, so simulation process is more complex. The research proposed that the RNG $k-\varepsilon$ model closed equations directly for the two order correlation of fluctuating velocity, and the determination of particle flow is ensured by the use of a DPM mode[6]. Because of there is the thin particles in the cyclone separator, the phase coupling is not considered, and the influence of the turbulent fluctuation is only considered. Meanwhile, the volume averaged conservation equation is discretized by the control volume finite element method, ANSYS 14 uses the isolation method to solve. The SIMPLE algorithm is adopted in the solution process, and the QUICK scheme is used to the convection term in the discrete scheme. Finally, this model shows the computational domain, containing 6682651 cells. The whole computational domain is divided by structured hexahedron grids.

\section{NUMERICAL SIMULATION RESULTS AND ANALYSIS}

In order to eliminate the influence of other operating factors, the simulation of each structure is carried out under the same operating parameters. Inlet flow velocity remains constant, which is $16.3 \mathrm{~m} / \mathrm{s}$, the particle size of the incident particles was Rosin-Rammler distribution. Particle size range is from to $0.075 \mu \mathrm{m} \sim 0.25 \mu \mathrm{m}$.

Table 1. Separation efficiency and pressure loss

\begin{tabular}{|c|c|c|c|c|}
\hline $\begin{array}{c}\text { Structure of } \\
\text { cyclone } \\
\text { separator }\end{array}$ & $\begin{array}{c}\text { Separation } \\
\text { efficiency } \\
\mathbf{( \% )}\end{array}$ & $\begin{array}{c}\text { Increase } \\
\text { ratio of } \\
\text { separation } \\
\text { efficiency } \\
(\mathbf{\%})\end{array}$ & $\begin{array}{c}\text { Pressure } \\
\text { loss } \\
\mathbf{( P a )}\end{array}$ & $\begin{array}{c}\text { Increase } \\
\text { ratio of } \\
\text { pressure } \\
\text { loss } \\
\mathbf{( \% )}\end{array}$ \\
\hline $\begin{array}{c}\text { Reference } \\
\text { structure }\end{array}$ & 95.2 & ------- & 925.6 & ------- \\
\hline$h_{c}=0.7 \mathrm{a}$ & 96.1 & 0.945378 & 1485.2 & 60.4586 \\
\hline$h_{c}=\mathrm{a}$ & 93.9 & -1.36555 & 1058.8 & 14.3855 \\
\hline$h_{c}=1.3 \mathrm{a}$ & 93.2 & -2.10084 & 960.6 & 3.7771 \\
\hline$h_{c}=1.6 \mathrm{a}$ & 92.3 & -3.04622 & 779.5 & 15.7893 \\
\hline Cylindrical & 85.3 & -10.3992 & 1127.6 & 21.8181 \\
guide pipe & & & & \\
\hline Entrance of & 94.7 & -0.52521 & 620.9 & 32.9186 \\
\hline square type & & & & \\
\hline
\end{tabular}

As shown in Table 1, reference structure is tapered entrance, and the length of the guide pipe is $5000 \mathrm{~mm}$, with the entrance height ratio is $1.25(5000 / 4000=1.25)$, Outlet pipe diameter is $3000 \mathrm{~mm}$.In the Table 1, pressure loss is the flow resistance loss of the square inlet section to the exit section of the exhaust pipe. Meanwhile, the increase ratio of pressure loss and separation efficiency is based on the numerical simulation results of the reference 
structure.

\subsection{Effect of inlet shape on separation efficiency and pressure loss}

Research shows that pressure drop and separation efficiency are the principal parameters which characterize the performances of a cyclone separator. We only study the influence of tangential normal inlet and tangential tapered inlet structure, while their entrance area and initial velocity of entry $\left(v_{0}=16.3 \mathrm{~m} / \mathrm{s}\right)$ are the same. So the treatment of flue gas is equal.

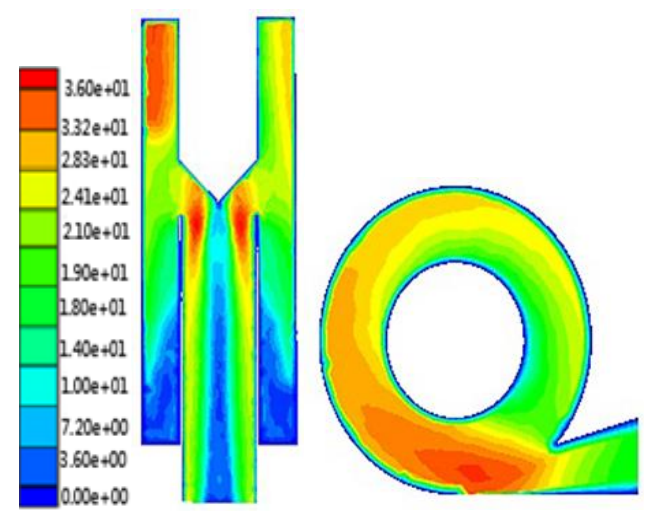

(a) Square cut converging entrance

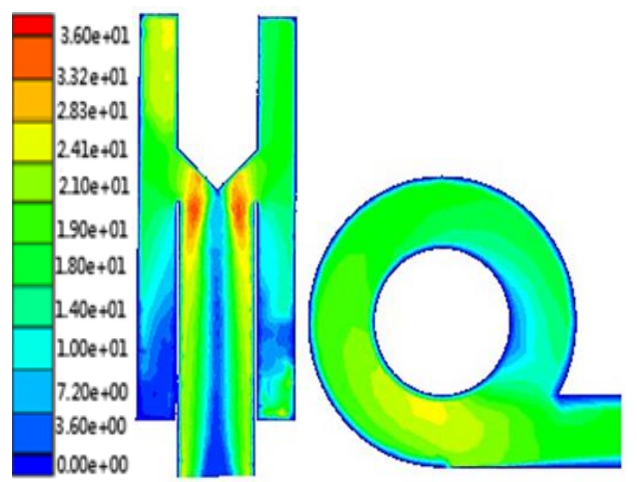

(b) Square cut normal type entrance

Figure 3. Comparison of velocity distribution under different entrance

As shown is Fig.3, when cyclone Separator is converging inlet, the speed of the area above the exhaust pipe is obviously increased. This is because the gas and solid mixture enters the tapered pipe, the inlet section is gradually reduced, which cause to the velocity of gas is increased. And the penetration ability of particles is also enhanced. More particles can pass through the vortex field to the wall of the separator. Meanwhile, the separation efficiency of the separator can be improved. Thus the above factors are taken into consideration: this article does not require the use of converging entrance structure.

\subsection{Effect of guide pipe on separation efficiency and pressure loss}

As shown is Fig.4, it is the numerical simulation results of two kinds of cyclone separators with different structures. Compared with a conical guide tube, the inlet velocity of the cylindrical guide pipe is larger, and a strong vortex is generated. Meanwhile, the cross section of the exhaust pipe suddenly reduced, resulting in a sudden increase in the speed of air whirling, which leads to the increase of pressure loss.

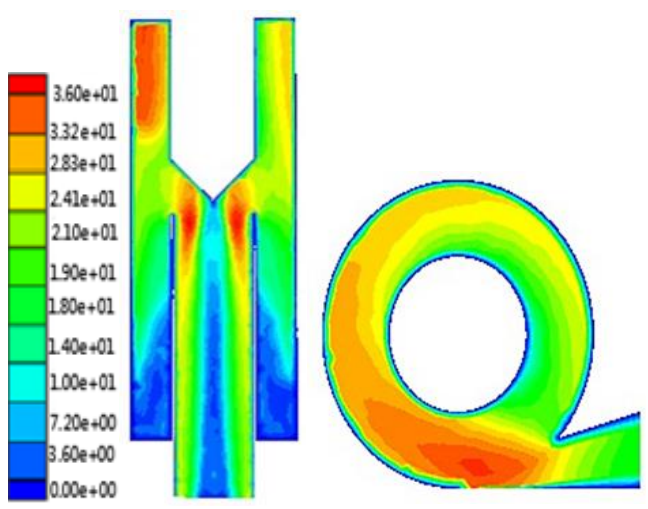

(a) The conical guide tube

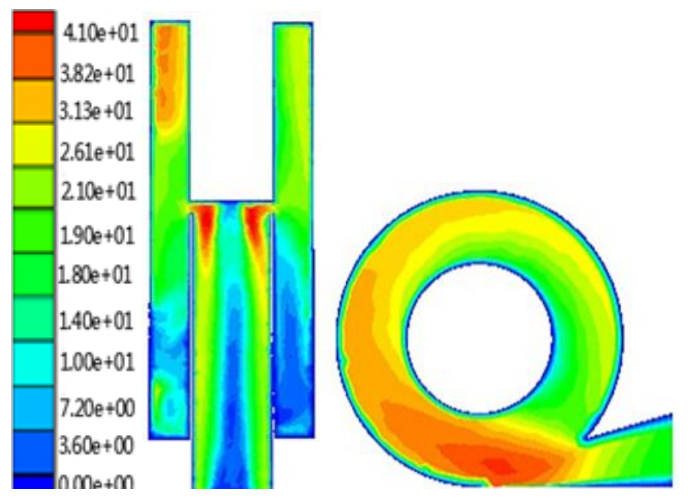

(b) The cylindrical guide pipe

Figure 4. Distribution of velocity

Can be seen from the Fig.5, Nearly all of the static pressure of the cylindrical guide pipe is larger than that of the conical guide pipe. Through the comprehensive analysis, the separation performance of the conical guide pipe is better than that of the cylinder guide pipe. 


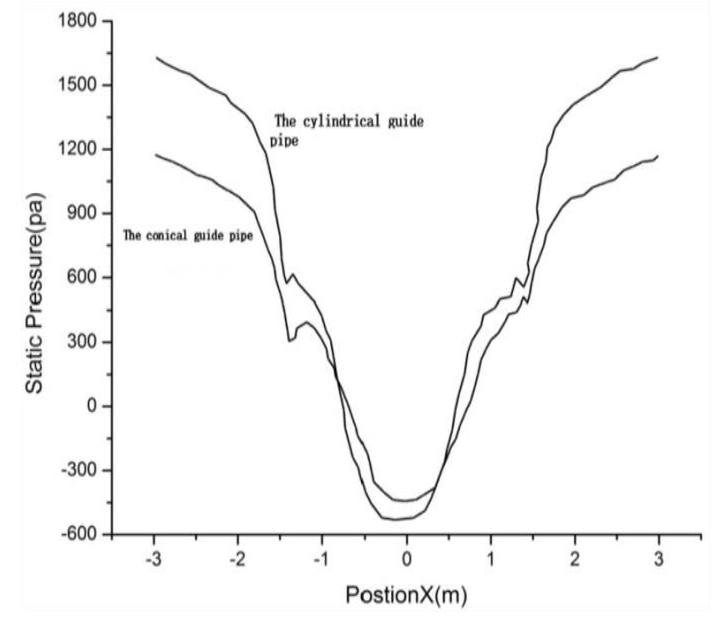

Figure 5. Comparison of static pressure distribution on the inlet diameter of exhaust pipe

\subsection{Effect of the guide pipe length $\left(h_{c}\right)$ on separation efficiency and pressure loss}

As shown is Fig.6, the velocity field change of the two cyclone is consistent. But the main difference is that strong swirl of exhaust pipe began to grow with $h_{c}$ increases, and longitudinal symmetry also increases. Thus we can draw a conclusion that the effect of $h_{c}$ closer to the $1.3 a$ will be more obvious. Through the comprehensive analysis, this paper selects $h_{c}=1.25 a$ as the most reasonable structure.

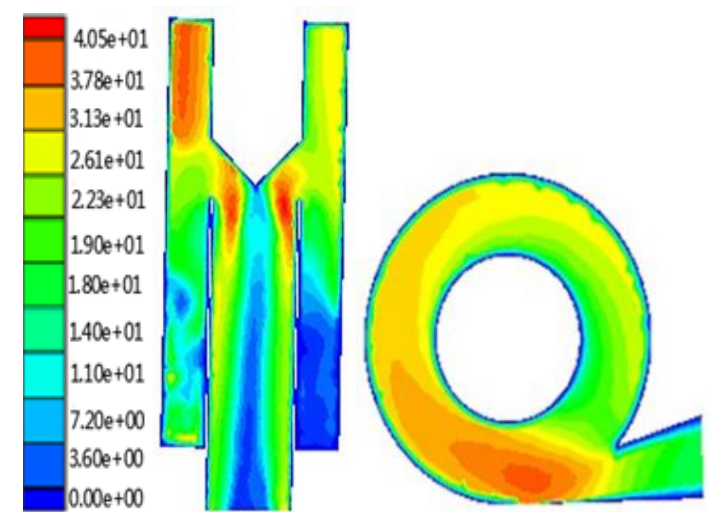

(a) $\quad h_{c}=a$

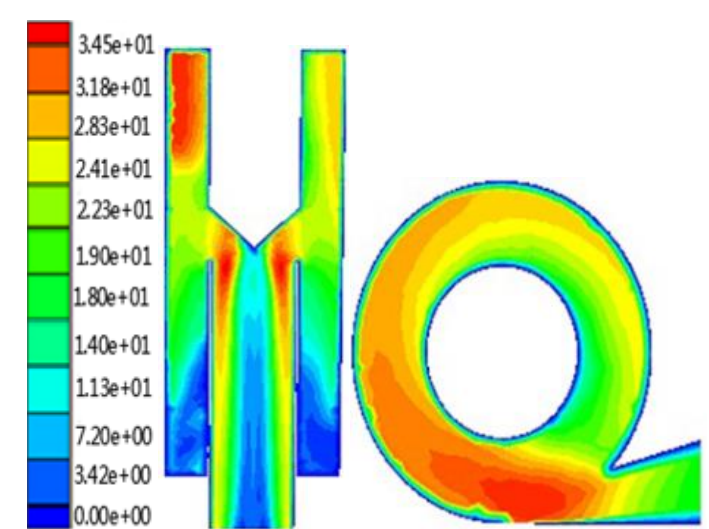

(b) $h_{c}=1.3 a$

Figure 6. Velocity distribution of $h_{c}=a$ and $h_{c}=1.3 a$

\section{CONCLUSIONS}

The DPM model provided by ANSYS software was applied to study flow field of a cyclone separator used in some circulating fluidized bed (CFB). Thus compared different simulation results with reference model, separator are optimized to provide reasonable theory guidance for the optimization of industrial design.

When the square cut converging inlet is employed, the separation efficiency of the cyclone separator increases as the velocity increases, while the vortex flow also increases and the pressure loss increases obviously.

Compared with conical guide pipe, the cylindrical guide pipe entrance has a higher velocity and a stronger vortex.

With a certain range, the selection of nozzle length needs a comprehensive consideration of the influence of the separation efficiency and pressure loss.

\section{References}

[1] K.W. Chu, B. Wang, D.L. Xu, et al. CFD-DEM simulation of the gas-solid flow in a cyclone separator. Chemical Engineering Science, 2011, 66(5): 834-847.

[2] K. Elsayed, C. Lacor. Optimization of the cyclone separator geometry for minimum pressure drop using mathematical models and CFD simulations. Chemical Engineering Science, 2010, 65(22): 6048-6058.

[3] J. Gimbun, T.G. Chuah, A. Fakhru'l-Razi, et al. The influence of temperature and inlet velocity on cyclone pressure drop: a CFD study. Chemical Engineering and 
Processing: Process Intensification, 2005, 44(1): 7-12.

[4] Oh J, Choi S, Kim J. Numerical simulation of an internal flow field in a uniflow cyclone separator. Powder Technology, 2015, 274:135-145.

[5] I. Mokni, H. Dhaouadi, H. Mhiri, et al. CFD Simulation Of The Flow Field In A Uniflow Cyclone Separator. Engineering Letters, 2009, 17(3): 173-177.

[6] P. González-Tello, F. Camacho, J.M. Vicaria, et al. A modified Nukiyama-Tanasawa distribution function and a Rosin-Rammler model for the particle-size-distribution analysis. Powder Technology, 2008, 186(3):278-281. 